\title{
A Colorimetric Microplate Assay for DNA-Binding Activity of His-Tagged MutS Protein
}

\author{
Michał Banasik $^{1} \cdot$ Paweł Sachadyn $^{1}$
}

Published online: 30 May 2016

(C) The Author(s) 2016. This article is published with open access at Springerlink.com

\begin{abstract}
A simple microplate method was designed for rapid testing DNA-binding activity of proteins. The principle of the assay involves binding of tested DNA by histagged protein immobilized on a nickel-coated ELISA plate, following colorimetric detection of biotinylated DNA with avidin conjugated to horseradish peroxidase. The method was used to compare DNA mismatch binding activities of MutS proteins from three bacterial species. The assay required relatively low amounts of tested protein (approximately $0.5-10 \mathrm{pmol})$ and DNA (0.1-10 pmol) and a relatively short time of analysis (up to $60 \mathrm{~min}$ ). The method is very simple to apply and convenient to test different buffer conditions of DNA-protein binding. Sensitive colorimetric detection enables naked eye observations and quantitation with an ELISA reader. The performance of the assay, which we believe is a distinguishing trait of the method, is based on two strong and specific molecular interactions: binding of a his-tagged protein to a nickel-coated microplate and binding of biotinylated DNA to avidin. In the reported experiments, the solution was used to optimize the conditions for DNA mismatch binding by MutS protein; however, the approach could be implemented to test nucleic acids interactions with any protein of interest.
\end{abstract}

Keywords DNA-protein binding $\cdot$ MutS $\cdot$ DNA mismatch $\cdot$ Nickel-coated microplate $\cdot$ His-tag

Paweł Sachadyn

psach@pg.gda.pl

1 Department of Molecular Biotechnology and Microbiology, Gdańsk University of Technology, ul. Narutowicza 11/12, 80-233 Gdańsk, Poland

\section{Abbreviations}

T49 The biotinylated oligonucleotide, $49 \mathrm{bp}$ in length, containing centrally located $\mathrm{T}$ in the position 25 , complementary to A49 (within the full length of oligonucleotide) and G49 (complementary within the full length of oligonucleotide except for the position 25 where a TG mismatch is formed) (see below)

A49 The non-biotinylated oligonucleotide, $49 \mathrm{bp}$ in length, containing centrally located $\mathrm{A}$ in the position 25

G49 The biotinylated oligonucleotide, $49 \mathrm{bp}$ in length, containing centrally located $\mathrm{G}$ in the position 25

TG49 dsDNA, 49 bp in length, biotinylated at one $5^{\prime}$ end, containing a TG mismatch in the position 25

TA49 Fully complementary dsDNA, 49 bp in length, biotinylated at one $5^{\prime}$-end

\section{Introduction}

DNA-protein interactions are critical for as fundamental biological processes as DNA replication, transcription, DNA recombination and repair. A number of methods addressing the cardinal problem of detecting DNA-protein complexes have been developed. Gel retardation $[1,2]$ or nitrocellulose filter binding assays [3] are the examples of simple, but rather time-demanding, approaches. The advanced methods such as surface plasmon resonance [4], laser scattering or atomic force microscopy [5] open more possibilities but they depend on sophisticated instruments.

Mismatch binding proteins known as MutS in prokaryotic and MSH in eukaryotic cells act as the guards of DNA 
replication fidelity [6]. MutS is the first element of DNA mismatch repair system found in most but not all prokaryotic organisms [7]. MutS recognizes a mispaired base in DNA, which triggers a sequence of events resulting in mismatch correction. A number of methods employing MutS for DNA mismatch detection have been developed [8-11]. Here we present a microplate assay that could be a convenient solution for the preliminary detection of DNA mismatch binding activity.

The method reported in this study has been designed in order to examine DNA binding to proteins immobilized on nickel-coated ELISA plates through the use of oligohistidine tags. The immobilized protein captures the tested biotin-labelled DNA fragments that are detected by avidin conjugated to horseradish peroxidase which catalyses a colorimetric reaction.

In the experiments presented herein, we implemented a solution to optimize the conditions for DNA mismatch binding by MutS proteins. However, this approach could be useful to examine DNA-binding properties of different proteins of interest.

\section{Materials and Methods}

\section{Preparation of Tested DNA Fragments}

The DNA fragments were prepared from synthetic oligonucleotides. The biotinylated oligonucleotide T49, BIOT-ACAGATCCACTGTGCGACGAGCTGTGCCGC ACGGTGATCGCAGCCGCTG was mixed with an equimolar amount of fully complementary A49, CAGCGG CTGCGATCACCGTGCGGCACAGCTCGTCGCACAG TGGATCTGT or almost fully complementary G49 CAG CGGCTGCGATCACCGTGCGGCGCAGCTCGTCGCA CAGTGGATCTGT in order to obtain fully complementary or mismatched DNA fragments, respectively. To prepare oligonucleotide duplexes, the mixtures of HPLC purified oligonucleotides were suspended in a buffer containing $10 \mathrm{mM}$ Tris- $\mathrm{HCl}\left(\mathrm{pH} 8.8 / 25^{\circ} \mathrm{C}\right), 50 \mathrm{mM} \mathrm{KCl}, 0.08 \%$ (v/v) Nonidet $\mathrm{P} 40$ and $5 \mathrm{mM} \mathrm{MgCl}_{2}$ in a final volume of $100 \mu \mathrm{l}$ to a final concentration of $10 \mu \mathrm{M}$, and subjected to heating and cooling $\left(92{ }^{\circ} \mathrm{C} / 120 \mathrm{~s}, 65^{\circ} \mathrm{C} / 120 \mathrm{~s}, 25{ }^{\circ} \mathrm{C} / 120 \mathrm{~s}\right)$.

\section{Protein Purification}

The recombinant MutS proteins were produced using Escherichia coli BL21(DE3)pLysS transformed with recombinant plasmid carrying the cloned mutS genes from Deinococcus radiodurans (DrMutS), Escherichia coli (EcMutS) and Thermus thermophilus (TthMutS), and purified using immobilized metal ion affinity chromatography (IMAC). Bacterial cell pellets were suspended in buffer A (50 mM phosphate buffer, $\mathrm{pH} 8.0 / 25^{\circ} \mathrm{C} ; 500 \mathrm{mM}$ $\mathrm{NaCl} ; 10 \%$ glycerol $(\mathrm{v} / \mathrm{v}))$ and disrupted by sonication on ice. Total lysate was centrifuged and the supernatant was collected and applied to cOmplete his-tag purification resin containing immobilized $\mathrm{Ni}^{2+}$ ions (Roche, cat. no. 05893682001) equilibrated with buffer $\mathrm{A}$. The column was washed with buffer A, following washing with buffer A supplemented with $10 \mathrm{mM}$ imidazole. The his-tagged MutS protein was eluted with ten $1 \mathrm{ml}$ portions of elution buffer A supplemented with $500 \mathrm{mM}$ imidazole, following dialysis against buffer $\mathrm{S}$ (50 mM phosphate buffer, $\mathrm{pH} 8.0$ / $25^{\circ} \mathrm{C} ; 200 \mathrm{mM} \mathrm{NaCl} ; 10 \%$ glycerol (v/v)) and concentration by centrifugation using ultrafiltration device with a $100 \mathrm{kDa}$ cut-off (Viva Science, cat. no. Z614661) to a final volume of $500 \mu \mathrm{l}$. The proteins were diluted with $50 \%$ $(\mathrm{v} / \mathrm{v})$ glycerol. Protein purity and concentration were determined by densitometric analysis of SDS-PAGE electropherograms.

\section{Protein Immobilization, DNA Mismatch Binding and Colorimetric Detection}

The microplate wells $\left(\right.$ Pierce $^{\circledR}$ Nickel Coated Plates, (Thermoscientific, cat. no. 15442, lot \#NH174556) were unblocked by washing with five $200 \mu \mathrm{l}$ portions of washing/binding buffer WB $(1 \times$ PBS buffer (Sigma, cat. no 79383, lot. BCBF0586) supplemented with $1 \%$ of Tween20 (Cat. No P7949, lot \#SZ2B2070V) and $5 \mathrm{mM} \mathrm{MgCl}_{2}$. One $\mu \mathrm{g}$ of his-tagged MutS protein was loaded per one microplate well in $100 \mu \mathrm{l}$ of the same buffer. After $15 \mathrm{~min}$ of incubation, the well was emptied, following washing with five $200 \mu \mathrm{l}$ portions of WB buffer and immediate loading of the tested biotinylated DNA (10 pmol) in $100 \mu \mathrm{l}$ of WB buffer. After 10 min of incubation, the excess of unbound DNA was removed by washing with five $200 \mu \mathrm{l}$ portions of WB buffer. DNA binding by the immobilized protein was detected with horseradish peroxidase conjugated to avidin (Extravidin, Sigma, cat. no. E2886, lot 098K4751). The well was loaded with $100 \mu \mathrm{l}$ of Extravidin 1000 times diluted in WB buffer and after $10 \mathrm{~min}$ of incubation washed with five $200 \mu \mathrm{l}$ portions of WB buffer, following immediate loading of $100 \mu \mathrm{l}$ of TMB $\left(3,3^{\prime}, 5,5^{\prime}\right.$ Tetramethylbenzidine) chromogenic substrate solution (Sigma, cat. no T0440, lot 051M1850). The colour reaction was developed for $15 \mathrm{~min}$, and the absorbance was measured with an ELISA reader (MultiSkan FC, ThermoScientific, cat. No. \#51190000) at $620 \mathrm{~nm}$. All steps of the protocol were carried out at room temperature. 


\section{Determination of DNA Mismatch Binding Affinity and Specificity}

The $\mathrm{A}_{620}$ absorbance values measured in the colour reaction were used to evaluate the affinity of MutS towards mismatched DNA and fully complementary DNA controls. The specificities were determined as the ratio of MutS affinity for mismatched to fully complementary DNA. In order to estimate background signals, the control experiments without DNA addition were performed. Statistical significance was determined with two-tailed heteroscedastic Student's t-test.

\section{Results}

The principle of mismatch DNA-binding assay by histagged MutS immobilized on a nickel-coated microplate is presented in Fig. 1. In brief, the his-tagged MutS protein is loaded to microplate wells to become immobilized after short incubation. The wells are emptied and washed to remove the unbound protein. For protein-DNA binding, the examined, biotinylated DNA fragments are added to the wells. After short incubation, the wells are emptied and washed in order to remove the unbound DNA. The captured DNA is detected with horseradish peroxidase conjugated to avidin. Avidin binds biotin labels of captured DNA, while horseradish peroxidase catalyses the oxidation of TMB chromogenic substrate, thus developing bluegreen colour. The results could be quantitated with an ELISA reader.

In order to examine mismatch DNA-binding properties of MutS, we compared the effects of capturing mismatched and fully complementary DNA. We designed an experimental setup where there are three microplate wells with immobilized his-tagged MutS. The mismatched DNA is added to the first well, while the fully complementary DNA and the loading buffer without DNA are loaded to the

A
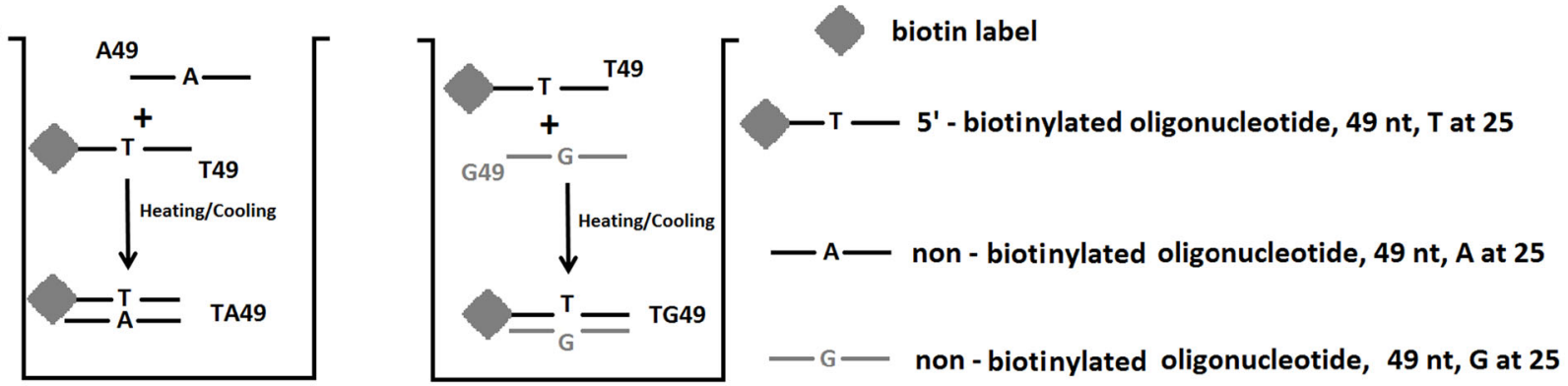

TA49, fully complementary 49 bp DNA, biotinylated at one of 5 ' - ends

${ }_{\mathrm{G}}^{\mathrm{T}}=\mathrm{TG} 49$, mismatched $49 \mathrm{bp}$ DNA, TG mismatch at 25 , biotinylated at one of $5^{\prime}$ - ends

B
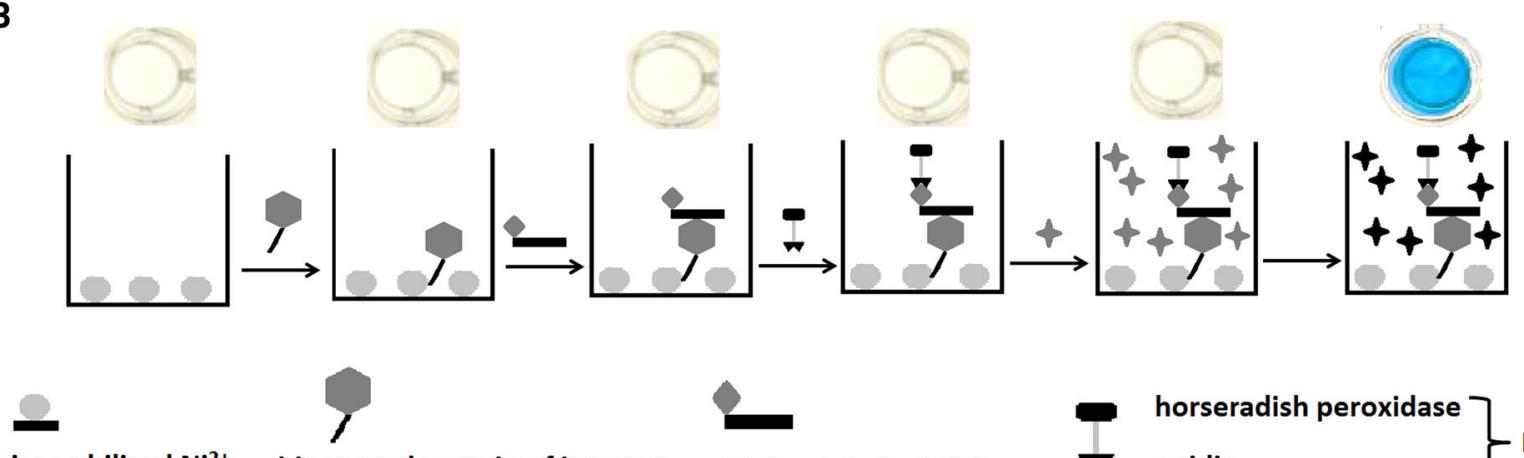

immobilized $\mathrm{Ni}^{2+}$

his-tagged protein of interest

biotin - labelled DNA

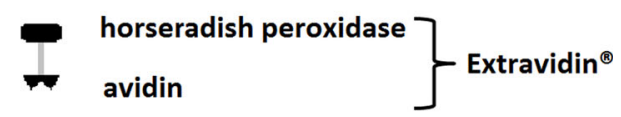

4

chromogenic substrate

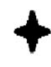

blue-green reaction product

Fig. 1 Principle of microplate colorimetric assay of DNA mismatch binding activity by his-tagged MutS. a preparation of mismatched and fully complementary DNA fragments; b protein immobilization, DNA mismatch binding and colorimetric detection 
second and third control wells, respectively. MutS-DNAbinding affinity is estimated as the absorbances obtained in the colorimetric assay. The specificity towards the mismatch is calculated as the ratio of the signal for mismatched DNA to that for fully complementary DNA.

\section{DNA Mismatch Binding Affinity and Specificity at Different Binding Conditions}

In order to find the conditions where MutS proteins show high affinity for DNA mismatches and low non-specific binding to fully complementary DNA, we tested the impact of salt concentration and ADP presence in the buffer used for DNA binding and washing. We contrasted the results obtained for the buffer containing $150 \mathrm{mM}$ salt (Figs. 2a, 3a) with those obtained for the buffer with doubled $(300 \mathrm{mM}$ ) salt concentration (Fig. 2b), and for the $300 \mathrm{mM}$ salt buffer with $1 \mathrm{mM}$ ADP addition (Fig. 2c). We performed the experiments with three different his-tagged MutS proteins from Escherichia coli, Deinococcus radiodurans, and Thermus thermophilus. The proteins used in the experiments were purified from recombinant overproducing E. coli strains, and the his-tag tails were introduced as the translational fusions at their $\mathrm{N}$-termini.

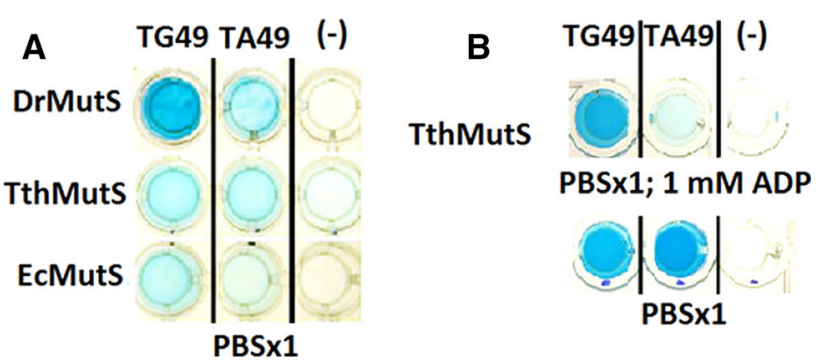

Fig. 3 Colorimetric detection of DNA binding by his-tagged MutS immobilized on a nickel-coated ELISA plate. a binding of his-tagged MutS proteins from D. radiodurans (DrMutS), T. thermophilus (TthMutS), and E. coli (EcMutS) to mismatched (TG49) and fully complementary (TA49) DNA; b the impact of $1 \mathrm{mM}$ ADP on MutS from T. thermophilus

As a result, we were able to find that under $300 \mathrm{mM}$ salt concentration the immobilized his-tagged MutS proteins exhibit both efficient binding of mismatched DNA and satisfactory specificity. Further, we observed that under the conditions of experiment, MutS from $D$. radiodurans showed a higher affinity towards mismatched DNA than those two others (Fig. 2a, b). In the presence of ADP, the specificity of MutS from $T$. thermophilus strongly increased (Fig. 3b) to exceed even that of MutS from $D$. radiodurans (Fig. 2c).

\section{A PBSx1 (150 mM salt)}

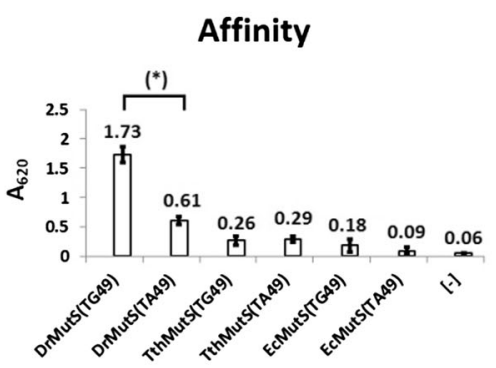

Specificity
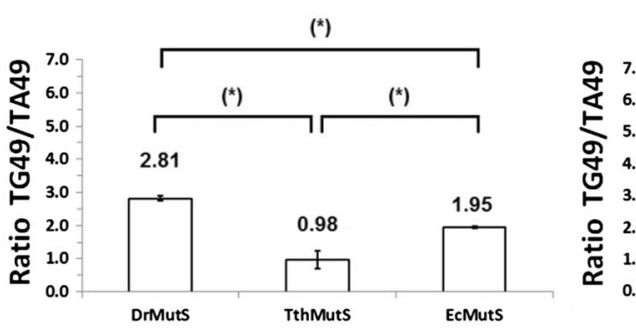

B $\quad 300 \mathrm{mM}$ salt (PBSx2)

\section{Affinity}

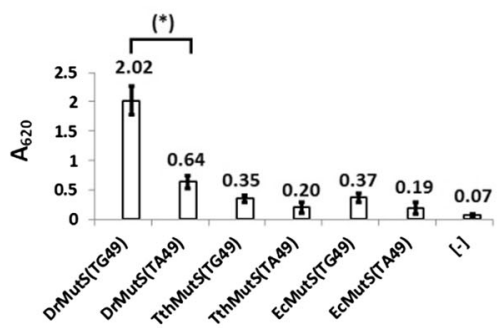

Specificity

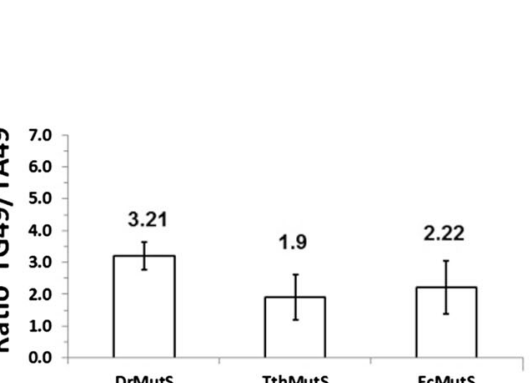

C $300 \mathrm{mM}$ salt (PBSx2); ADP (1 mM)

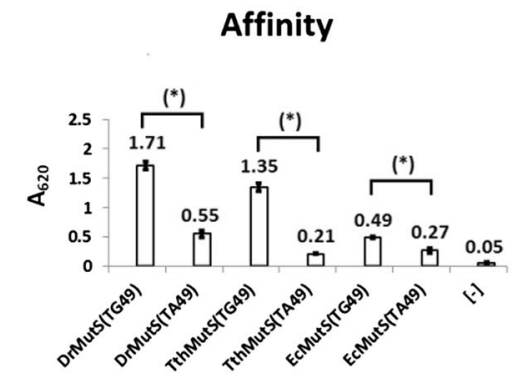

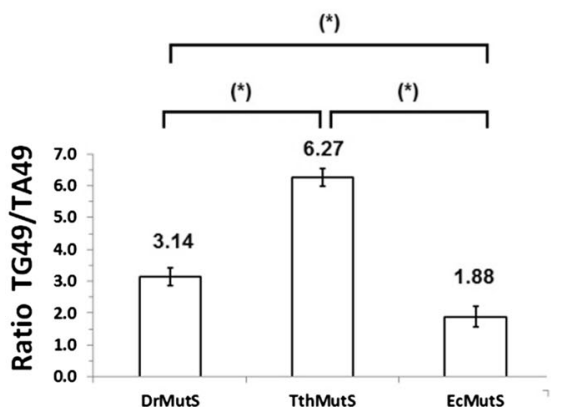

Fig. 2 Impact of salt concentration and ADP on DNA mismatch binding by MutS proteins from three bacteria: D. radiodurans (DrMutS), T. thermophilus (TthMutS), and E. coli (EcMutS). The critical parameters of the experiments were as follows: a $150 \mathrm{mM}$ salt concentration (PBSx1); b $300 \mathrm{mM}$ salt concentration (PBSx2);

c $1 \mathrm{mM}$ ADP presence. The specificities were calculated as the ratio of affinities (absorbance values) for the mismatched (TG49) to fully complementary DNA (TA49). The background signal [-] is marked for comparison. Each experiment was repeated 3 times. Statistical significance was indicated with asterisks $(*)$ 


\section{Impact of DNA Concentration and Protein Amount}

We performed two series of experiments in which either the amount of DrMutS protein added to the wells was kept constant $(1 \mu \mathrm{g})$, while the DNA concentrations varied in the range of $0.0001-1.0 \mu \mathrm{M}$ (Fig. 4a) or the concentration of loaded DNA was at the constant level $(0.1 \mu \mathrm{M})$, whereas the amounts of loaded DrMutS varied from 0.05 to $2 \mu \mathrm{g}$ (Fig. 4b). The obtained absorbance values were correlated with increasing amounts of either added DNA (Fig. 4a) or loaded MutS protein (Fig. 4b). The series of DNA-binding tests was performed in the buffer containing $150 \mathrm{mM}$ salt without ADP addition, which corresponds to the conditions of the experiment presented in Fig. 2a. The measurements showed that the absorbance changed linearly with the increasing concentrations of loaded DNA within the range 0.001-0.1 $\mu \mathrm{M}$ (Fig. 4a, inset). Also, the results indicate that the working amounts of loaded his-tagged protein correspond to the range of $1-20 \mathrm{pmol}$ (Fig. $4 \mathrm{~b}$, inset). A slight improvement in DNA mismatch binding specificity
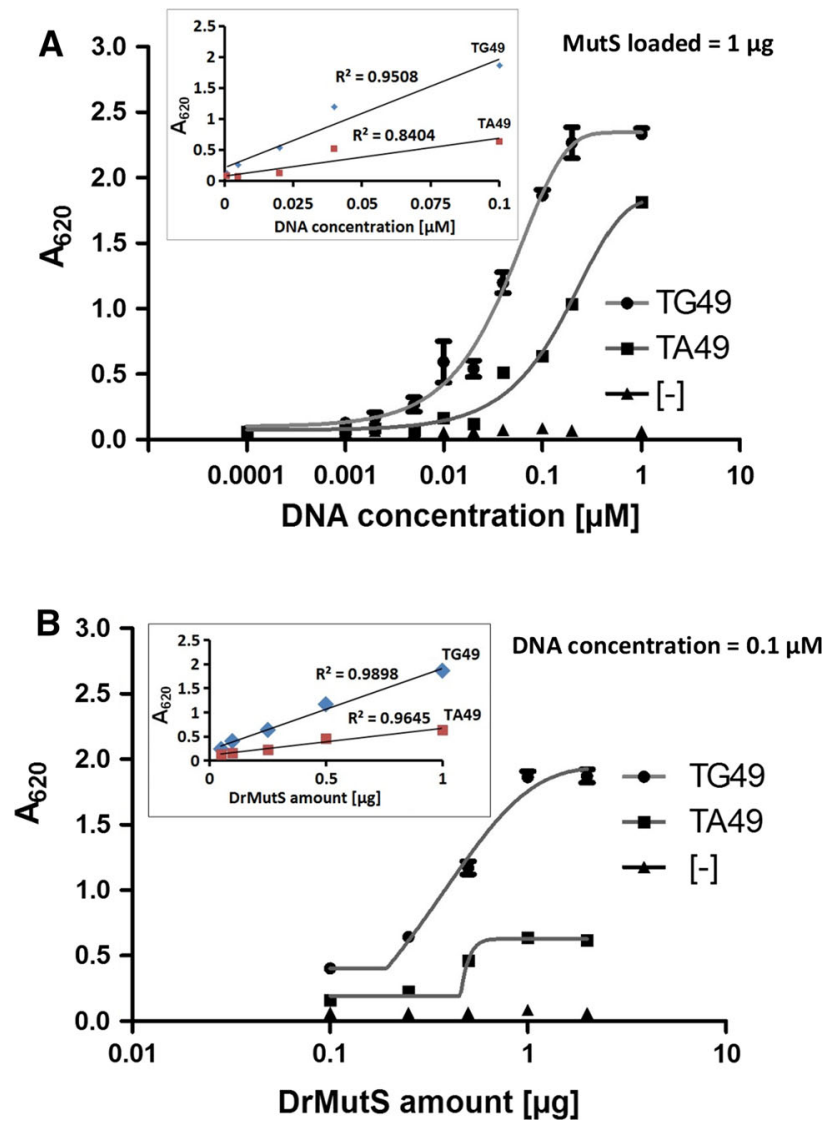

Fig. 4 The impact of increasing amounts of DNA and MutS. The impact of increasing concentrations of DNA during binding with MutS (a) and amounts of loaded DrMutS (b) on the $\mathrm{A}_{620}$ absorbance. The ranges of linear analysis are shown in the insets. The specificities towards mismatched DNA are presented in Fig. 5 could be observed at lower amounts of loaded DNA (Fig. 5a). Changing the amounts of loaded MutS did not have an essential impact on specificity towards mismatched DNA (Fig. 5b). However, lowering DNA concentrations results in a decrease of colorimetric signal (Fig. 4a).

\section{Evaluation of Detection Sensitivity}

The microplate assay with $1 \mu \mathrm{g}$ of his-tagged-MutS loaded for immobilization was demonstrated to allow reliable detection of captured biotinylated DNA following binding in $100 \mu \mathrm{l}$ volume at the concentrations ranging from 0.001 to $0.1 \mu \mathrm{M}$ (Fig. 4a). In order to evaluate the limits of detection, the assay was performed for a series of decreasing DNA concentrations of mismatched DNA $(0.01,0.001$, $0.0001 \mu \mathrm{M})$ and prolonged time of colorimetric reaction (Fig. 6). The results showed that the signal for $10^{-4} \mu \mathrm{M}$ was close to the background level. In the case of DNA concentrations of 0.01 and $0.001 \mu \mathrm{M}$, the colorimetric signal could be easily discriminated from that of background. Nevertheless, we would recommend applying a higher working concentration of biotinylated DNA of $0.1 \mu \mathrm{M}$, where stronger signals are produced, as more useful to test different binding conditions (Fig. 2). Extending the time of colorimetric
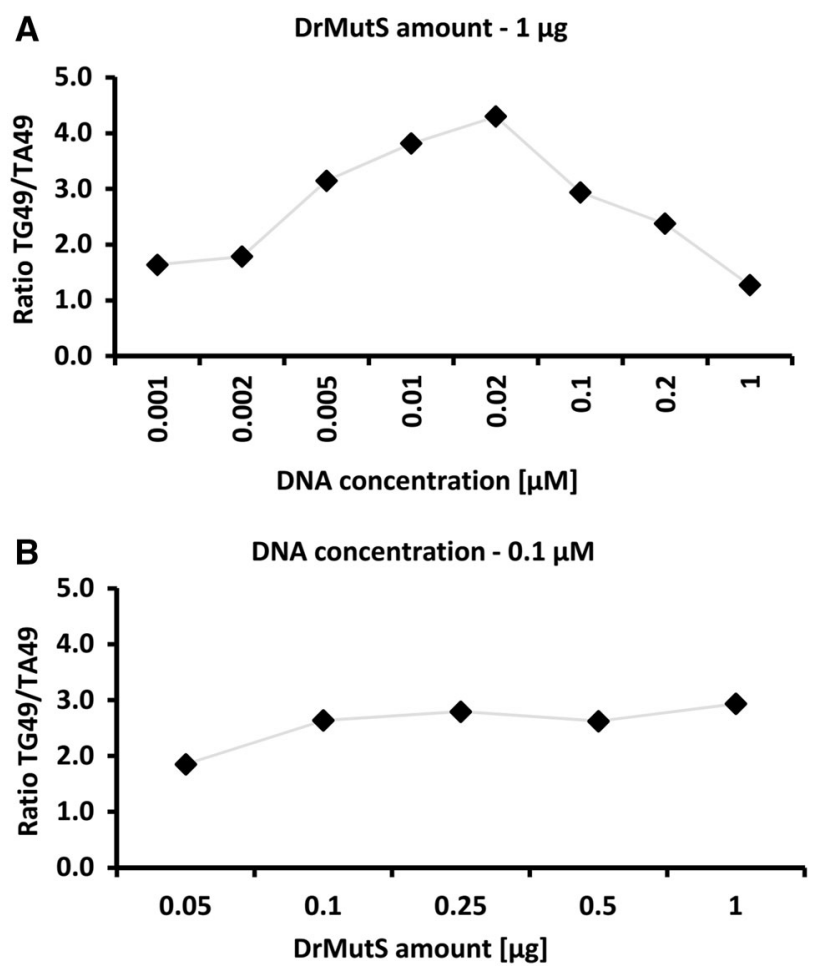

Fig. 5 The effect of MutS and DNA amounts on the specificity towards DNA mismatches at different DNA concentrations (a) and amounts of DrMutS (b) loaded. The specificity is defined as the ratio of signals for the mismatched DNA to fully complementary DNA. The signal values $\left(\mathrm{A}_{620}\right.$ absorbance) are indicated in Fig. 4 


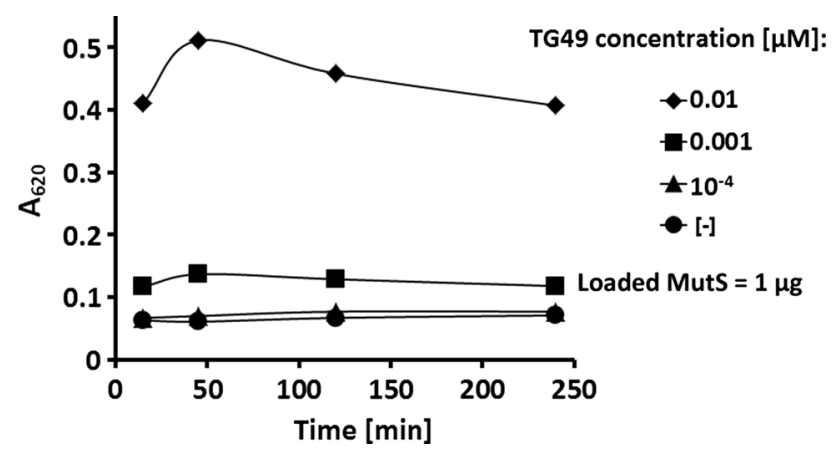

Fig. 6 Prolonged time of colorimetric reaction does not enhance the sensitivity of DNA mismatch binding detection

reaction from 15 to $245 \mathrm{~min}$ did not result in significant improvement of detection limit, while approximately a $25 \%$ increase in signal was observed after a 45-min as compared to a 15 -min reaction.

\section{Discussion}

The microplate colorimetric assay we developed was useful to optimize DNA mismatch binding conditions and to compare the properties of his-tagged MutS proteins from three different bacteria: T. thermophilus, E. coli, and D. radiodurans.

We think that this approach could be implemented for testing interactions of nucleic acids with different proteins, on condition that an oligohistidine tag is added to the protein under examination and the nucleic acid substrate could be biotinylated. Other fusion tags than oligohistidine and other microplates than those nickel-coated, as well as other types of DNA labelling than biotin could be considered; however, we believe that the solutions we chose contributed to the assay performance. The advantages of the assay include:

- convenient protein immobilization on nickel-coated microplates;

- relatively low amounts of examined proteins$0.54-10.8$ pmol per well (50 ng-1 $\mu$ g of $92 \mathrm{kDa}$ MutS monomer);

- relatively low amounts of tested DNA-0.1-10 pmol per well;

- low background signal owing to low binding solid phase of plastic microplates;

- non-radioactive labelling;

- relatively short time of experiment (up to $60 \mathrm{~min}$ )

- simple colorimetric detection-results could be observed with naked eye (Fig. 3) and quantitated with an ELISA reader.
Conditions such as ionic strength, $\mathrm{pH}$, and the presence of cofactors or detergents could be easily modified, which facilitates testing of different factors influencing DNAprotein interactions. In contrast to gel retardation and filter binding assays, in this method, the protein-DNA interactions are examined in a buffer of choice. The necessity of adding the his-tag to the examined protein may be regarded as a complication; however, engineering an oligohistidine fusion domain is one of the preferred solutions used for rapid protein purification in molecular studies. The application of plastic solid phase allows low non-specific binding, but this is the addition of $1 \%$ of Tween- 20 which is a critical, and the absence of this reagent in the washing/ binding buffer may result in a dramatic increase of background signal.

We designed the method for rapid assessment of protein-DNA binding. Considering the colorimetric signal changes linearly within some range of increasing DNA concentrations, the method allows relative quantitation of DNA-binding efficiencies. Nevertheless, we would not recommend using lower amounts of protein and DNA, as it may decrease detection sensitivity. Enzymatic colorimetric reaction enabled reliable detection of mismatched DNA binding at the concentrations of $0.01-0.1 \mu \mathrm{M}$. However, it should be underlined that we report the concentrations of loaded DNA, while the exact amounts of bound DNA are not determined in the assay.

\section{Concluding Remarks}

A number of ELISA assays are broadly applied to examine protein-DNA interactions [9], including a few solutions reporting the use of nickel-coated microplates $[12,13]$. The practical usefulness which distinguishes the assay we propose is based on two strong and specific molecular interactions: binding of his-tagged proteins to nickelcoated microplates and binding biotinylated DNA to avidin, as well as the sensitive detection with horseradish peroxidase. We recommend this approach for preliminary screening of DNA-binding proteins and for optimization of DNA-protein binding conditions.

Acknowledgments The study was supported by a research grant from the Polish Ministry of Scientific Research and Information Technology No. N302 271837. We would like to thank Ewa Maria Hildebrandt, M.Sc. Eng., who contributed to cloning the gene of Deinococcus radiodurans mutS.

\section{Compliance with Ethical Standards}

Conflict of Interest The authors declare no commercial or financial conflict of interest. 
Open Access This article is distributed under the terms of the Creative Commons Attribution 4.0 International License (http://crea tivecommons.org/licenses/by/4.0/), which permits unrestricted use, distribution, and reproduction in any medium, provided you give appropriate credit to the original author(s) and the source, provide a link to the Creative Commons license, and indicate if changes were made.

\section{References}

1. Stanislawska-Sachadyn, A., et al. (2005). Preliminary studies on DNA retardation by MutS applied to the detection of point mutations in clinical samples. Mutation Research, 570(1), 97-103.

2. Stanislawska-Sachadyn, A., et al. (2003). Construction and purification of his6-Thermus thermophilus MutS protein. Protein Expression and Purification, 28(1), 69-77.

3. Whitehouse, A., et al. (1997). Analysis of the mismatch and insertion/deletion binding properties of Thermus thermophilus, HB8, MutS. Biochemical and Biophysical Research Communications, 233(3), 834-837.

4. Blackwell, L. J., et al. (2001). Distinct MutS DNA-binding modes that are differentially modulated by ATP binding and hydrolysis. Journal of Biological Chemistry, 276(36), 34339-34347.

5. Yang, Y., et al. (2005). Determination of protein-DNA binding constants and specificities from statistical analyses of single molecules: MutS-DNA interactions. Nucleic Acids Research, 33(13), 4322-4334.

6. Jiricny, J. (2013). Postreplicative mismatch repair. Cold Spring Harbor Perspectives in Biology, 5(4), a012633.

7. Sachadyn, P. (2010). Conservation and diversity of MutS proteins. Mutation Research/Fundamental and Molecular Mechanisms of Mutagenesis, 694(1), 20-30.

8. Stanisławska-Sachadyn, A., \& Sachadyn, P. (2005). MutS as a tool for mutation detection. Acta Biochimica Polonica, 52(3), 575 .

9. Sachadyn, P., Stanisławska-Sachadyn, A., \& Kur, J. (2007). A bifunctional chimeric protein consisting of MutS and betagalactosidase. Journal of Biotechnology, 127(2), 229-234.

10. Stanisławska-Sachadyn, A., et al. (2006). The construction of bifunctional fusion proteins consisting of MutS and GFP. Journal of Biotechnology, 121(2), 134-143.

11. Sachadyn, P., Stanislawska, A., \& Kur, J. (2000). One tube mutation detection using sensitive fluorescent dyeing of MutS protected DNA. Nucleic Acids Research, 28(8), e36-e40.

12. Zhao, L., \& Stoddard, B. L. (2014). Rapid determination of homing endonuclease DNA binding specificity profile. In D. R. Edgell (Ed.), Homing endonucleases: methods and protocols (pp. 127-134). Totowa: Humana Press.

13. Yang, W. C., \& Swartz, J. R. (2011). A filter microplate assay for quantitative analysis of DNA binding proteins using fluorescent DNA. Analytical Biochemistry, 415(2), 168-174. 